whereas the ADHD+DCD group scored significantly lower in tests involving exposure to multisyllabic (2-5) non-word pairs and speech discrimination with a working-memory load. The low performance in the ADHD children with complicating DCD was the result of impaired memory rather than of speechdiscrimination problems. (Norrelgen F, Lacerda F, Forssberg H. Speech discrimination and phonological working memory in children with ADHD. Dev Med Child Neurol May 1999;41:335-339). (Respond: Dr F. Norrelgen, MotorikLab, Astrid Lindgrens Children's Hospital, Stockholm, S-171 76, Sweden).

COMMENT. Language problems are reported in $65 \%$ of children with ADHD and motor-perception impairments (DCD), and hyperactive behavioral disorders affect approximately the same proportion of children with learning disabilities. Phonological awareness and working memory are important in the acquisition of reading and writing skills. The present study suggests that deficits in working memory may contribute to the high incidence of dyslexia among children with $\mathrm{ADHD}$, and may explain their motor-perception impairments by effects on storage of motor commands at an early age. See Denckla MB, In Progress in Pediatric Neurology II, 1994;pp173-176, for an account of the phonological-linguistic basis of dyslexia, its anatomic-phsiologic correlates, and the overlap between reading disability and other learning disabilities with "ADD $(\mathrm{H}) . "$

\title{
METHYLPHENIDATE IN ADHD PRESCHOOLERS WITH DISABILITY
}

The safety and efficacy of methylphenidate (MPH), 0.3 and $0.6 \mathrm{mg} / \mathrm{kg}$, in 11 preschool children (aged 4-5 years) with developmental disabilities and attention deficit hyperactivity disorder (ADHD) were determined in a double-blind, placebocontrolled, crossover study at the Western Psychiatric Institute, University of Pittsburgh, PA. IQs ranged from 40 to 78 (mean, 60). No child had autism/PDD. A positive response to MPH was obtained in $73 \%$. Teacher ratings of hyperactivity and inattention and clinic-based observations of compliance and activity level were significantly improved. Adverse MPH side effects in 5 (45\%) patients included severe social withdrawal, crying, and irritability. (Handen BL, Feldman HM, Lurier A, Murray PJH. Efficacy of methylphenidate among preschool children with developmental disabilities and ADHD. LAm Acad Child Adolesc Psychiatry July 1999;38:805-812). (Reprints: Dr Handen, Merck Program, Western Psychiatric Institute and Clinic, 3811 O'Hara St, Pittsburgh, PA 15213).

COMMENT. Preschool children with ADHD and developmental disabilities respond to $\mathrm{MPH}$ at rates similar to those of school-age children with mental retardation and $\mathrm{ADHD}$, but the risk of adverse drug effects is greater. Social withdrawal and irritability are frequent, especially at higher doses. A combination approach, behavioral intervention and lower MPH dose, might reduce the risk of side effects.

Are stimulants overprescribed? is addressed in a study of the diagnosis and treatment of ADHD in four US urban/suburban communities, including Puerto Rico (Jensen PS et al. I Am Acad Child Adolesc Psychiatry July 1999;38:797-804). Only $12.5 \%$ of children with a diagnosis of ADHD had received stimulant medication in the previous 12 months. Mental health counseling and/or schoolbased interventions were used more often than medication. Stimulants are not overprescribed, and their potential effectiveness may be neglected due to cultural or physician bias or lack of parent education. 